\title{
COUPLING CAVITY DAMPER FOR THE ARES
}

\author{
F. Naito, K. Akai, N. Akasaka, E. Ezura, T. Kageyama, H. Mizuno, \\ H. Nakanishi, Y. Takeuchi, Y. Yamazaki \\ KEK, High Energy Accelerator Research Organization, 1-1 Oho, Tsukuba, 305 Japan \\ T. Kobayashi \\ Institute of Applied Physics, Tsukuba Univ., 1-1 Ten-nodai, Tsukuba, 305 Japan
}

\section{Abstract}

The coaxial (WX120D) antenna damper has been developed for damping the parasitic 0 and $\pi$ modes of the KEKB ARES cavity. It is installed in the coupling cavity of the ARES. The damper consists of a disk-type coaxial ceramic window and a cross stub angle. The damper has a broadband $\mathrm{rf}$ property in order to absorb the rf power of the parasitic modes. The cross angle is utilized for supplying the cooling water to the antenna. The damper was designed by using a computer simulation code without a cold model test. Finally the properties of the damper has been confirmed by the high-power and the beam test for the ARES cavity.

\section{INTRODUCTION}

Accelerator Resonantly coupled with Energy Storage (ARES) has been developed for the KEK B-factory [1,2]. The ARES is an effective countermeasure against the coupled-bunch instability due to the accelerating mode in KEK B-factory. It is composed of three cavities: an accelerating cavity, an energy storage cavity and a coupling cavity. Thus ARES has three modes: the $0, \pi / 2$ and $\pi$ modes. The resonant frequencies of them are about 505, 509 and $513 \mathrm{MHz}$ respectively. The operation mode is the $\pi / 2$ mode. The parasitic $\pi$ and 0 modes must be damped, because they contribute to the longitudinal coupled bunch instability. For damping them, an antenna damper has been installed in the coupling cavity in which both $\pi$ and 0 modes have an rf-field but the $\pi / 2$ mode has no field. The ARES with the coupling cavity damper is shown in Fig.1 [3].

Our practical targets for the damper are as follows:

(1) The damper reduces the loaded $Q$ values of the $\pi$ and 0 modes.

(2) The damper can handle the average rf power of a few $\mathrm{kW}[4]$.

The following $\mathrm{rf}$ property is required to achieve the targets described above;

(3) the VSWR of each components of the damper is less than about 1.2 in the frequency range from 500 to 520 $\mathrm{MHz}$.

The damper which fills our requirements is shown in Fig. 2. The dimensions of the damper is shown in Fig. 3. The damper is comprised of an antenna, an rf window and a cross stub angle. The rf properties of every components of the damper were calculated by using a computer simulation code (HFSS) [5]. The details of the design are reported in the following section.

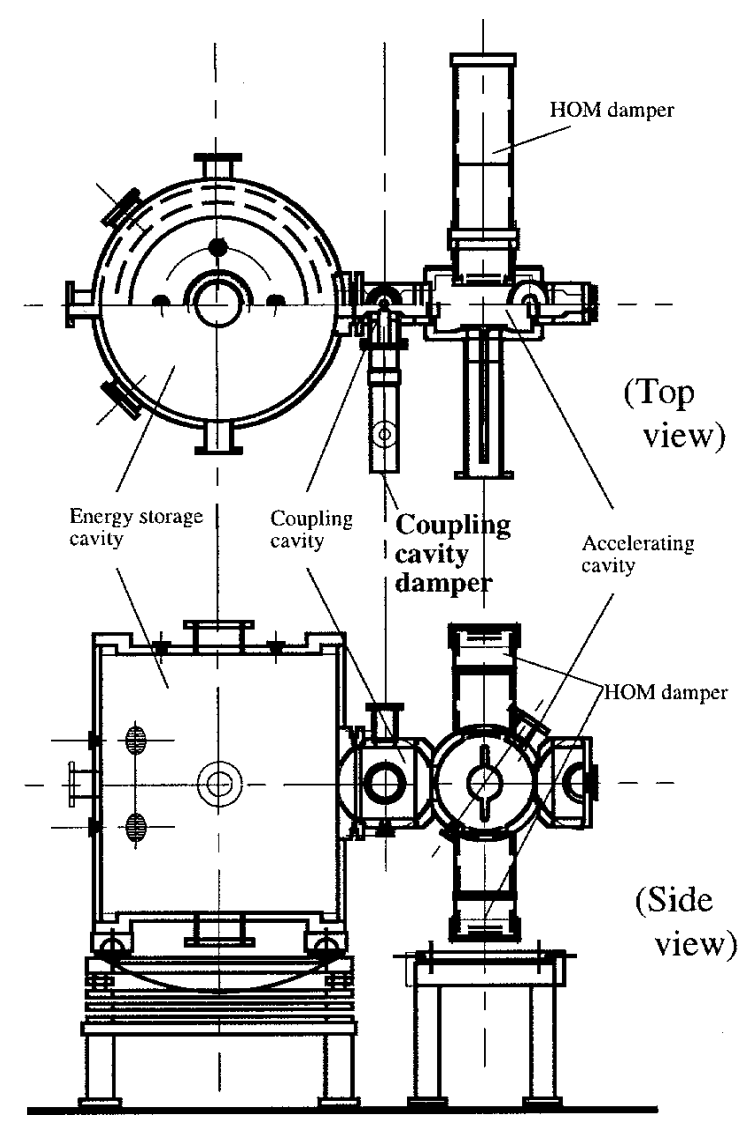

Figure 1: Schematic view of the ARES [3]

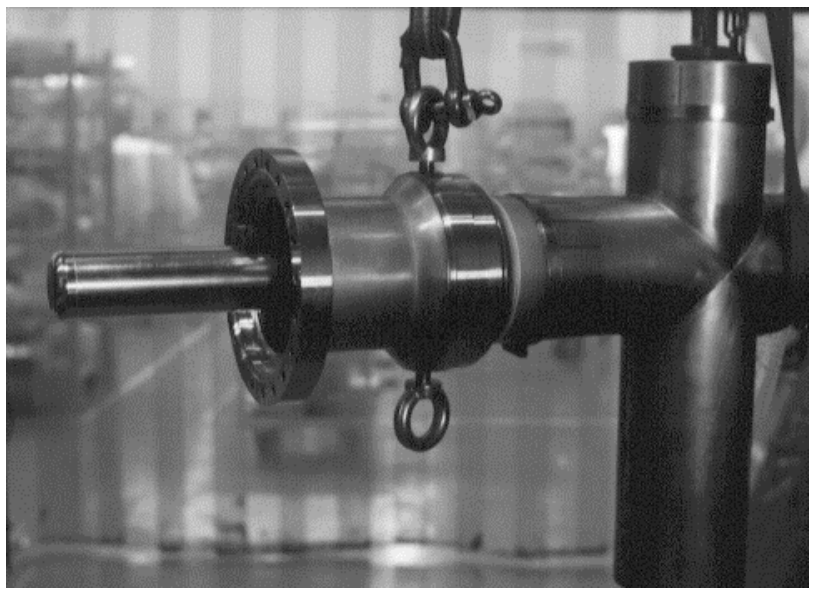

Figure 2: Photograph of the high-power model of the coupling cavity damper [2] 


\section{RF WINDOW}

The coaxial ceramic (95\% pure Alumina) disk is used for the $\mathrm{rf}$ window in the damper. The outer and the inner diameter of the window are $140 \mathrm{~mm}$ and $40 \mathrm{~mm}$ respectively. The thickness of the window is $8 \mathrm{~mm}$. The surface of the vacuum side of the window has $10 \mathrm{~nm}$ thin TiN coating in order to reduce the electron emission coefficient of the ceramic surface. The impedance is matched by using an under- and an over-cut structure of the coaxial waveguide around the window. The underand the over-cut window structure is also used in the input coupler of the ARES [6]. The values of $\mathrm{S}_{11}$ calculated for the window by HFSS are plotted in Fig. 4. The $S_{11}$ values are small enough around the operation frequency.

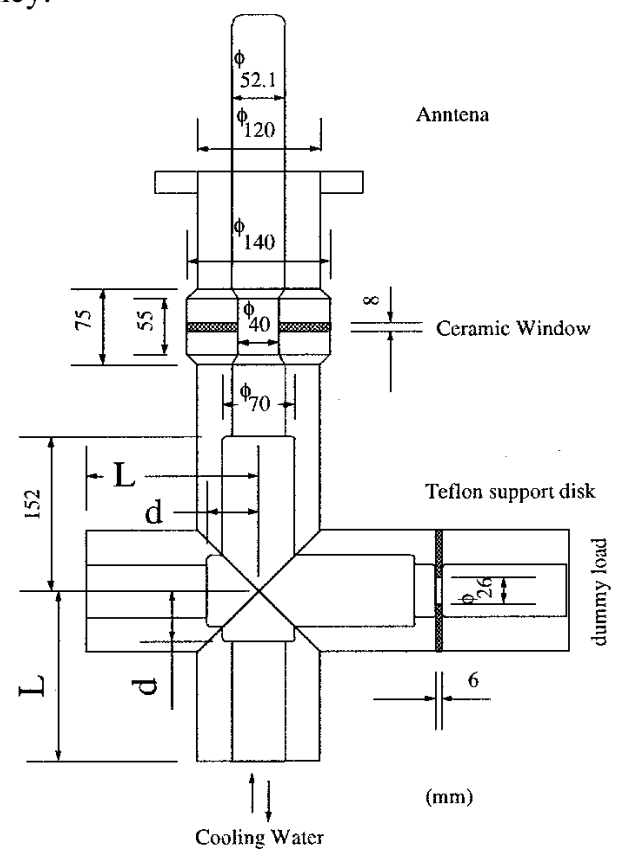

Figure 3: Schematic view of the coupling cavity damper

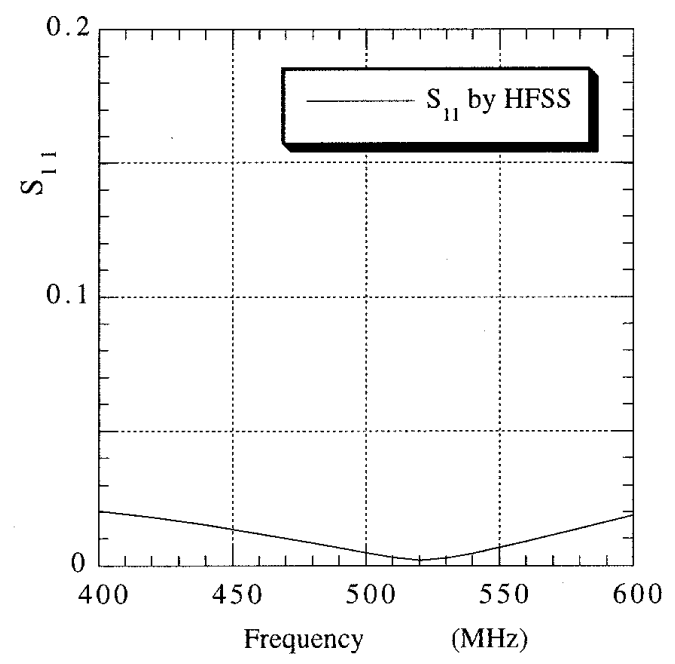

Figure 4: Calculated $\mathrm{S}_{11}$ for the ceramic window

\section{CROSS STUB ANGLE}

The damper is terminated by a coaxial dummy load in order to absorb the rf-power of the parasitic modes. Unfortunately we can not supply the cooling water to the antenna through the dummy load, because the water cooling system of the dummy load is closed itself. Thus we make use of a stub angle as a line of the cooling water of the antenna. Since the rf band width of the damper is chiefly limited by that of the stub, it is very important to find the broadband stub angle structure.

The structure we finally chose is the cross stub angle shown in Fig. 3. The diameter of the inside cylinder of the coaxial waveguide near the angle is enlarged in order to get the desired broadband rf property [7]. The calculated results of $\mathrm{S}_{11}$ for the cross angle are shown in Fig. 5 with two parameters $L$ and $d$ which are seen in Fig. 3. The values of $\mathrm{L}$ and $\mathrm{d}$ in the original design are 175 $\mathrm{mm}$ and $35 \mathrm{~mm}$ respectively. The original value of $\mathrm{d}$ was increased by $15 \mathrm{~mm}$ to $50 \mathrm{~mm}$ during the production of the damper in order to solve an assembling problem. By the change of the dimension, the frequency of the $\mathrm{S}_{11}$ minimum point was shifted. It is shown by the dot line in Fig. 5. However the VSWR is still small enough in the desired frequency range. Thus the cross angle with these dimensions was used for the first high-power and the beam test.

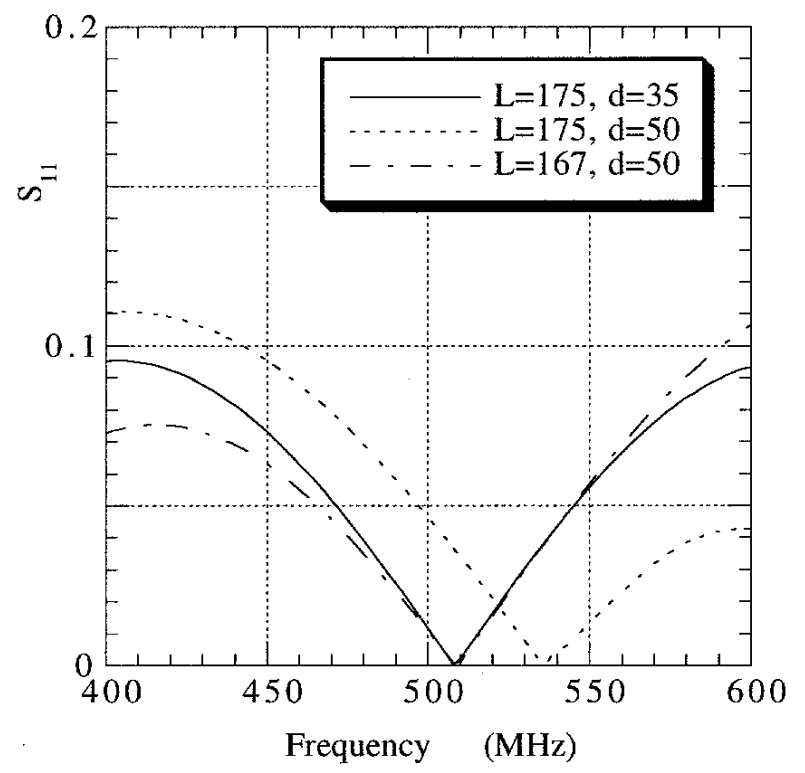

Figure 5: Calculated $\mathrm{S}_{11}$ parameter for the cross-stub $\mathrm{L}$ and $\mathrm{d}$ are shown in figure 3 .

Figure 5 shows one more line $(\mathrm{d}=167 \mathrm{~mm}, \mathrm{l}=50 \mathrm{~mm})$ which has the almost same frequency dependence as that of the originally designed cross angle. We are going to use these values for the next coupling cavity damper of the ARES.

Figure 6 shows the $S_{11}$ values for the damper includes the rf window and the cross stub angle with a Teflon bead support. It shows that the VSWR of the damper is small enough in the very wide frequency range. 


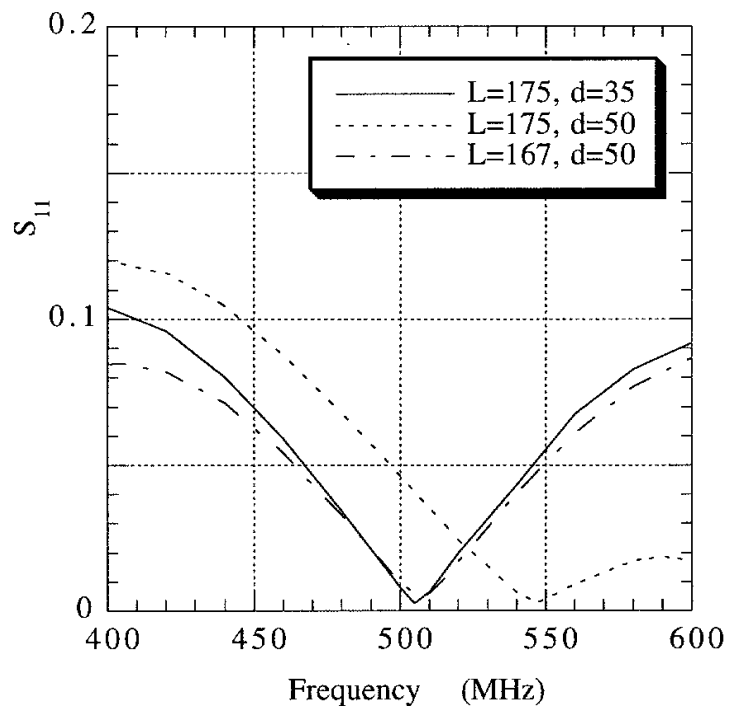

Figure 6: Calculated $\mathrm{S}_{11}$ for the damper includes the ceramic window and the cross stub angle with the Teflon bead support.

\section{ANTENNA}

The external $\mathrm{Q}$ value $\left(\mathrm{Q}_{\mathrm{c}}\right)$ of the antenna to the coupling cavity has been estimated by the phase shift of the reflected RF wave from the coupling cavity. The phase shift values were calculated by HFSS as a function of the rf frequency. (The calculation method is described in the references [8,9].) The calculated $\mathrm{Q}_{\mathrm{c}}$ is about 56 on the condition that the insertion length of the antenna into coupling cavity is $10 \mathrm{~mm}$ from the wall of the coupling cavity.

The equivalent circuit analysis shows that the loaded $\mathrm{Q}$ value $\left(\mathrm{Q}_{\mathrm{L}}\right)$ of the $\pi$ and 0 modes are approximately two times of the $\mathrm{Q}_{\mathrm{c}}$ [1]. Thus the expected $\mathrm{QL}_{\mathrm{L}}$ is about 112 for the $\pi$ and the 0 modes.

If the $Q_{L}$ values are too large to suppress the contribution from the parasitic modes to the longitudinal coupled instability, we can easily increase the insertion length more in order to reduce the $Q_{L}$ values of $\pi$ and 0 modes.

\section{EXPERIMENTAL RESULTS}

The $\pi / 2$ mode and damped $\pi$ and 0 modes of ARES are shown in Fig. 7 which was measured for the high-power ARES cavity with the coupling cavity damper [2]. The measured QL values of the $\pi$ and the 0 modes are about 100. The measured $\mathrm{Q}_{\mathrm{L}}$ values are consistent with the calculated values described in the previous section.

During the high-current beam experiment by the accumulator ring (AR) in TRISTAN, the measured power flow from the damper was about $1 \mathrm{~kW}$ for the $100 \mathrm{~mA}$ single-bunch beam. Although it is very preliminary result, it does not contradict with the estimation $[3,10]$.

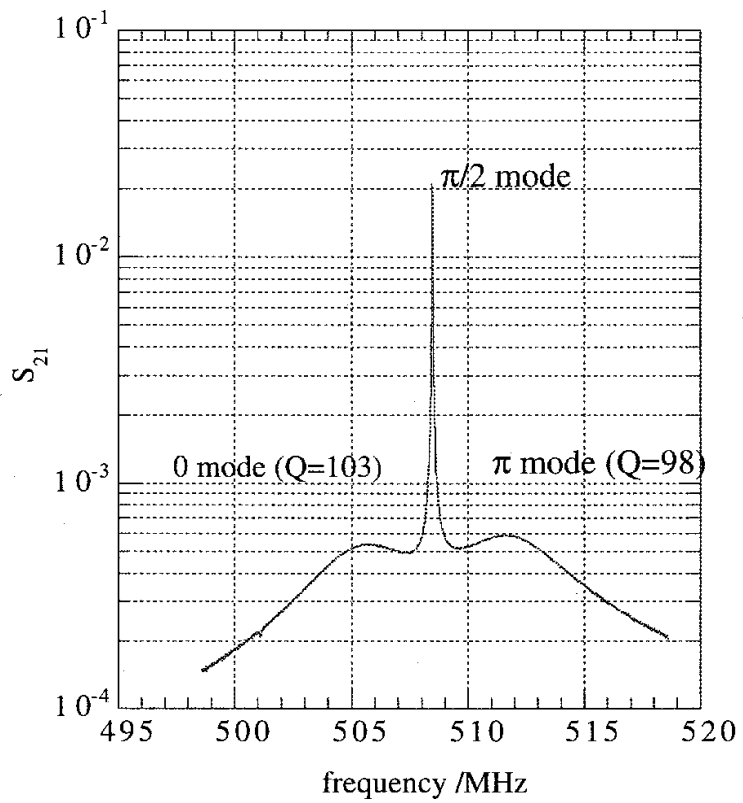

Figure 7: The $\pi / 2$ mode and the damped 0 and $\pi$ modes measured for the high-power ARES cavity [2].

\section{CONCLUSION}

The coaxial (WX120D) antenna damper with the ceramic window and the cross stub angle has been developed in order to damp the parasitic 0 and $\pi$ modes of the KEKB ARES cavity. The damper was installed in the coupling cavity of the high-power ARES cavity and it has been tested by the high-current beam experiment in the AR of the TRISTAN. Measured properties for the damper are consistent with the estimated values.

\section{REFERENCES}

[1] Y. Yamazaki and T. Kageyama, Part. Accel., 44, p107 (1994)

[2] T. Kageyama, et al, Proc. 5th European Part. Accel. Conf., p2008 (1996)

[3] T. Kageyama, et al, "Development of high-power ARES cavities", in this conference.

[4] K. Akai, et al, Proc. 5th European Part. Accel. Conf., p1994 (1996)

[5] HP Part No. 85180A, Hewlet Packard Corp.

[6] F. Naito, et al, Proc. 5th European Part. Accel. Conf., p2014 (1996)

[7] G. L. Ragan "Microwave Transmission Circuit", McGraw-Hill, New-York, p170 (1948)

[8] J.C. Slater "Microwave Electronics", D.Van Nortrand, Princeton, p84 (1950)

[9] T. Kageyama, KEK Report 89-4, 1989.

[10] N. Akasaka, et al, "Fundamental mode characteristics of ARES cavity under beam environment", in this conference. 